\title{
Nurse's Clinical Skill Utilisation: An Opinion from Public Health Institutions
}

\author{
Santosh Mahindrakar ${ }^{1}$, Mansingh Jat ${ }^{2}$, Besty Ann Varghese ${ }^{3}$ \\ ${ }^{1}$ Research Coordinator IAPH New Delhi, ${ }^{2}$ Nursing Officer, All India Institute of Medical Sciences, New Delhi, \\ ${ }^{3}$ Nursing Officer, All India Institute of Medical Sciences, New Delhi
}

\begin{abstract}
Background: Nurses are the backbone of health care systems worldwide. In India the assessment of existing knowledge of nursing workforce and the utilization of skills is not evaluated and properly used to ensure good quality in health care.
\end{abstract}

Method: Using the Delphi technique a survey was developed and sent to nurses. Self- rating method (on a likert scale) were used in order to operationalize the personal skills.

Results: Almost half (48\%) of the participants have a Bachelor degree. Out of this $27.2 \%$ qualified for a higher education (e.g. Master in related subject). Most nurses (56\% in sample were females) are permanent employed working as staff nurse or nursing officers in the public sector. Among the participants $20 \%$ have sufficient teaching experience between 1 to 3 years. Self-rating of skills was high in almost all topics.

Conclusion: Having attained higher education most of the participants remain working as staff nurses. The good self-rating of participants underlines their ability to take over much higher positions and responsibilities. Moreover, teaching experience is hardly acknowledged by institutions since teaching staff is usually recruited from outside. The study suggests that a majority of the population has an interest to work in rural area .Better work conditions are needed in order to gain workforce in this areas.

Skills should effectively utilized in areas of administration, management, research and education, with a proper distribution to rural and urban areas in order to ensure a good health care system in India.

Keywords: Utilization of nursing skills, nursing skills, public health nurses, India.

\section{Introduction}

Admittedly, human resources for health, which are involved in the production, protection and improvement of population health, still remains as an underdeveloped zone without receiving much attention for metamorphism. ${ }^{1}$ This situation pertains since decades in India, irrespective of the various measures employed by the World Health Organization (WHO) for the same. Unfortunately, India still lacks adequate health workforce. Nurses, being the backbone of health sector, play a pivotal role in placing the population into

\section{Corresponding Author: Santosh Mahindrakar}

Research Coordinator IAPH New Delhi the trajectory of a healthy nation. However as stated by Rao et al $^{2}$ nurses are not given appropriate power to implement various health measures, as observed in other developed countries. As per WHO, there is a wide disparity in the distribution of human resources, and there are major concerns based on their number, deployment, inadequacy of training as well as improper expertise mix. ${ }^{3}$ Mentioned disparities are usually observed along with poor human resource management, absence of appropriate career ladder, inadequate work conditions, and without much room for professional development. Hence, it is the need of the hour to obtain adequate, latest and trustworthy data of this major workforce to obtain an evidence base, without which adequate planning would be inappropriate. It involves a delve into the matter, to analyze whether the right people are placed at right quantity in the right position, and without this 
information, a proper decision making in the health care development, would be an impossibility. It was found that many studies are not undertaken in this area and among this health care population.

Thus, a study was undertaken among the nurses working in public health institutions with the objective to assess the existing knowledge and skill utilization of nursing workforce in the public health sector.

\section{Methodology}

Survey method was adopted to achieve the defined objective. A tool was formed using the Delphi technique. A set of expertise was identified and the tool was sent to them for validation and the same was adopted. Google form inbuilt consent form was sent to a list of friends and later they sent to their known. A snow-ball technique was used to select the convenient samples. Reminders were sent to the first set of known participants and then requested to spread a word among their friend group. There were 409 responses in total during the period of 30 days.

\section{Result}

Around half (48\%) of the participants had Bachelors degree as a basic education, few of them had additional qualification like Bachelors in other subject, certificate courses related to skill, post graduate diploma in hospital management/administration and masters in other health subjects like Public Health, Human Resource management. The clinical nurses were pursuing additional and higher education to update their skills and knowledge but these are skills are not yet recognized. There is a further need to evaluate to the lack their skill recognition. .

More than $3 / 4$ of the participant's designation was clinical nurse/nursing officer, $56 \%$ were female, and $79.2 \%$ were permanent workers in the public health institutions.

Most of the participants want to work in the native places when they are provided with good working conditions. There were many studies reporting nonavailability of the specialist at rural public health institutions. Nurses who are experienced in the tertiary care hospitals with hand on skills are not allowed to go back and work in their native places. $\quad \mathrm{A} \mathrm{r} \mathrm{o} \mathrm{u} \mathrm{n} \mathrm{d}$ half of the participants had more than five years and $1 / 4$ of the participants had more than a decade of clinical experience.

Table 1: Baseline information of the participants

\begin{tabular}{|c|c|c|}
\hline Variables & Frequency & Percentage \\
\hline \multicolumn{3}{|l|}{ Educational status } \\
\hline General Midwifery and Nursing & 101 & 24.8 \\
\hline $\mathrm{BSc}$ & 196 & 48.0 \\
\hline MSc & 103 & 25.2 \\
\hline $\mathrm{PhD}$ & 8 & 2.0 \\
\hline \multicolumn{3}{|l|}{ Additional qualification } \\
\hline None & 325 & 79.6 \\
\hline Bachelor of Arts & 11 & 2.7 \\
\hline Certificate & 15 & 3.7 \\
\hline Diploma & 28 & 6.8 \\
\hline Masters & 27 & 6.6 \\
\hline Multiple & 2 & .5 \\
\hline \multicolumn{3}{|l|}{ Designation } \\
\hline Clinical Nurse & 311 & 76.2 \\
\hline Nurse educator & 54 & 13.2 \\
\hline Research & 20 & 4.9 \\
\hline Supervisor & 8 & 2.0 \\
\hline Community Health Officer (CHO) & 5 & 1.2 \\
\hline Public Health Nurse (PHN) & 5 & 1.2 \\
\hline Unemployed & 5 & 1.2 \\
\hline \multicolumn{3}{|l|}{ Type of contract } \\
\hline Contract & 85 & 20.8 \\
\hline Permanent & 323 & 79.2 \\
\hline \multicolumn{3}{|l|}{ Years of clinical experience } \\
\hline Up to 5 yrs & 208 & 51.0 \\
\hline $5-10$ & 96 & 23.5 \\
\hline $10-15$ & 62 & 15.2 \\
\hline $15-20$ & 17 & 4.2 \\
\hline $20+$ & 25 & 6.1 \\
\hline \multicolumn{3}{|l|}{ Teaching experience } \\
\hline No & 212 & 52 \\
\hline $0-5$ & 154 & 37.7 \\
\hline $5-10$ & 22 & 5.4 \\
\hline $10+$ & 20 & 4.9 \\
\hline \multicolumn{3}{|l|}{ Utilization of knowledge } \\
\hline 1.0 & 31 & 7.6 \\
\hline 2.0 & 36 & 8.8 \\
\hline 3.0 & 81 & 19.9 \\
\hline
\end{tabular}




\begin{tabular}{|l|c|c|}
\hline Variables & Frequency & Percentage \\
\hline 4.0 & 118 & 28.9 \\
\hline 5.0 & 115 & 28.2 \\
\hline Missing & 27 & 6.6 \\
\hline Utilization of Skill & & \\
\hline 1.0 & 25 & 6.1 \\
\hline 2.0 & 33 & 8.1 \\
\hline 3.0 & 84 & 20.6 \\
\hline 4.0 & 113 & 27.7 \\
\hline 5.0 & 125 & 30.6 \\
\hline Missing & 28 & 6.0 \\
\hline Rural area work & & \\
\hline No & 42 & 10.5 \\
\hline Yes & 310 & 76.0 \\
\hline May be & 55 & 13.5 \\
\hline
\end{tabular}

\begin{tabular}{|l|c|c|}
\hline Variables & Frequency & Percentage \\
\hline Specialty & & \\
\hline No & 63 & 15.4 \\
\hline Yes & 304 & 74.5 \\
\hline Not mentioned & 41 & 10 \\
\hline Gender & & \\
\hline Female & 228 & 55.9 \\
\hline Male & 173 & 42.4 \\
\hline Not mentioned & 7 & 1.7 \\
\hline Institution & & \\
\hline Public & 349 & 85.5 \\
\hline Private & 46 & 11.3 \\
\hline Not mentioned & 13 & 3.2 \\
\hline
\end{tabular}

Table 2: Cross table between the qualification and clinical nurses

\begin{tabular}{|c|c|c|c|c|c|}
\hline & \multicolumn{2}{|c|}{ Clinical } & \multicolumn{2}{|c|}{ Non clinical } & \multirow{2}{*}{ P Value } \\
\hline & Frequency & Percentage & Frequency & Percentage & \\
\hline GNM & 85 & $25.8 \%$ & 15 & $20.3 \%$ & \multirow{4}{*}{.000} \\
\hline $\mathrm{BSc} N$ & 176 & $53.5 \%$ & 18 & $24.3 \%$ & \\
\hline $\mathrm{MSc} N$ & 67 & $20.4 \%$ & 34 & $45.9 \%$ & \\
\hline $\mathrm{PhD}$ & 1 & $.3 \%$ & 7 & $9.5 \%$ & \\
\hline Total & 329 & $100 \%$ & 74 & $100.0 \%$ & \\
\hline
\end{tabular}

Table 3: Comparison of clinical and non-clinical nurses with their clinical and teaching experiences

\begin{tabular}{|l|l|c|c|c|c|c|}
\hline \multicolumn{2}{|c|}{} & N & Mean & Std. Deviation & Std. Error Mean & P Value \\
\hline \multirow{3}{*}{ Clinical experience } & Clinical & 329 & 7.998 & 6.5274 & .3599 & .001 \\
\cline { 2 - 8 } & Non Clinical & 74 & 5.014 & 6.7634 & .7862 & .15419 \\
\hline \multirow{2}{*}{ Teaching experience } & Clinical & 329 & 1.2678 & 2.79670 & .78388 & .000 \\
\cline { 2 - 8 } & Non Clinical & 74 & 5.7677 & 6.74320 &. \\
\hline
\end{tabular}

Mean clinical experience among the clinical nurses is higher than non- clinical and mean teaching experiences among the non- clinical higher than clinical nurses and statistically significant. It is a point to note that among the clinical nurses, $20.4 \%$ of them completed and have teaching experiences of $1.3 \pm 2.8$ years and clinical experiences of $8 \pm 6.5$ years. Most of these tertiary hospitals are attached with nursing institutions are doing direct recruitment of the teaching staff rather than promoting these skilled nurses with adequate qualification within an institution.

\section{Discussion}

Nurses and their demographic profile: In the study, it was found that the larger population had Bachelor's Degree (48\%) and it almost constituted half of the population. The remaining half was almost equally composed of Diploma holders and postgraduates. However, this is in contrast to the Delhi Nursing Council (DNC) Statistics of 2015, ${ }^{4}$ where the largest group was that of Diploma holders (55.1\%), followed by that of B.Sc Nurses (39.4\%) and the least (5.5\%) was that of 
auxiliary nurses. Unfortunately, they did not have an account of the nurses who have attained any other higher degrees.

A characteristic, which was revealed from the study, was that the larger proportions of nurses (55.9\%) were females. Only $42.4 \%$ were males, and $1.7 \%$ of the population, did not mention their gender. These findings are similar to a study conducted by Gupta et al., 2003, to assess the health workforce, in which it was proved that about $62 \%$ of health sector was occupied by women and it was attributed that this skew was due to the female dominance in nursing. It was also commented in the study that nursing, in spite of being a highly complex skilled profession, has not received a market value in accordance to the level of skills involved in it, courtesy, perception of it as "women's work". 5

\section{Nurses' interest to work in rural or urban areas}

The study reveals that a majority of the population has an interest to work in rural areas. However, as per the WHO report on human workforce by Anand and Fan, ${ }^{6}$ only $39.6 \%$ of nurses work in rural sector and among them, only $9.9 \%$ of them had a medical qualification. The rest $67.1 \%$ had qualification less than secondary schooling, 9.3\% had technical or non- technical diploma, $23.7 \%$ had basic or post graduate degree. Also, 73 districts had no nurses with a medical qualification. According to the study, about $85.5 \%$ of the nurses are working in public sector. But, this is in contrast to the study done by Karan et al. ${ }^{7}$ where about three- fourth of the nurses were employed in private sector. An appropriate and equal distribution of nurses in rural and urban areas, and in public and private sector is a mandate to ensure universal access to healthcare.

Utilization of nursing competencies-skill and knowledge: According to the study, when the participant nurses were asked to rate the utilization of their knowledge on a 5-point scale, the highest proportion of them rated it as 4 and 5, accounting to about $28.9 \%$ and $28.2 \%$, respectively. At the same time, $19.9 \%$ of them rated it at $3,8.8 \%$ at 2 and $7.6 \%$ at 1 . On the other hand, when the utilization of skills were assessed, largest group of them, that is $30.6 \%$ and $27.7 \%$ of them felt that it was at 5 and 4, on the rating scale, respectively. However, $34.8 \%$ of them felt that their skills were under- utilized, irrespective of the high level of training and expertise they have attained. About 6-7\% of participants missed to give this information. Though there are few studies on assessing the competencies of nurses, this was a pioneer study in the perception of the extension to which nursing competencies are exploited.

Implications: It is evident from the study that, our nation has a handful of qualified experienced efficient nurses, but unfortunately, their knowledge and skills are not employed, as how it should be ideally done. The resources, that a developing nation like India possess, is ample enough to uplift the existing skewed health care system to a better and balanced one, where "Health For All" can be assured. However, a comprehensive and practical system should be introduced for the same to deploy qualified nurses in the right areas. Implementation of dual system of nursing will be a great step towards proper utilization of clinical knowledge and skills for the betterment of the patients, nursing students and nurses. The administrative and decision-making skills of postgraduate nurses should be exploited right from their productive young age, rather than waiting for a minimum of two decades for them to get promoted to the post of nurse manager. If promotion system is re-structured based on knowledge, skills, qualification, experience and the interest to keep oneself updated with the recent evidence-based practices, that will be a great impetus to the nursing practice, administration, education and the profession itself.

Some of the recommendations for further studies are: Comparative study on the skills of nurses as perceived by self and rated by an observer and analytical study to find the hindering factors in proper utilization of nursing skills

\section{Conclusion}

Nurses, the mainstay of health sector face many challenges today, which demand an interrogation and analysis into the situation. We have an ample supply of qualified nurses, but their skills and abilities remain obscure, as they lack adequate and fair opportunities. If these skills are effectively utilized in areas of health practices, administration, management, and research with a proper distribution to rural and urban areas, then health care services quality improve with better outcome. It is recommended that, in institutions where nursing colleges are also a part of it, they should recruit the nursing faculty within the clinical pool of nurses; at least a higher percent of the seats if reserved for them, would be beneficial for both the employee and the employer. This would not only motivate the former, 
but also, would aid in reducing the cost burden for the latterin appointing and training an external candidate.

If all these pitfalls of nursing workforce are not addressed in the right manner, at the right time, our well- qualified nurses will go in search of greener pastures to foreign nations, where they can grow multi- dimensionally, thereby, resulting in a crisis in our nation's healthcare sector, with acute shortage of efficient nurses, in the near future itself.

Ethical Approval: We did not take ethical approval from any ethical committee but we followed the ICMR guidelines in all the steps verified by experts.

Source of Funding: It's self funded. We authors did not receive any funding from any organization for this study.

\section{Conflict of Interest: Nil}

\section{References}

1. Nandan D, Agarwal, D. Human Resources for Health in India: Urgent Need for Reforms. Indian J Community Med.; 37:205-6.Available from: http:// www.ijcm.org.in/text.asp?2012/37/4/205/103464

2. Rao M, Rao, K D, Kumar S, Chatterjee M, Sundararaman T. Human resources for health in India. The Lancet. 2011 Feb 11; 377(9765):587-598. http://doi.org/10.1016/S0140-6736(10)61888-0.
3. WHO. Toolkit on monitoring health systems strengthening: Human Resources for Health. 2009 May. Available from https://www.who.int/ healthinfo/statistics/toolkit_hss/EN_PDF_Toolkit_ HSS_HumanResources_oct08.pdf.

4. Delhi Nursing Council. Nurses StatisticsYear wise. 2015. Available from https://www. delhinursingcouncil.com/Nurses-Statistics.asp

5. Gupta N, Diallo K, Zurn P, Dal Poz MR. Assessing human resources for health: what can be learned from labour force surveys? [Internet]. Human resources for health. BioMed Central; 2003 [cited 2020 Sep. 24]. Available from: https://www.ncbi. nlm.nih.gov/pmc/articles/PMC179883/

6. Anand S \& Fan V. (2016). The health workforce in India: Human Resources for Health Observer Series No. 16. World Health Organization. https://www. who.int/hrh/resources/16058health_workforce India.pdf(cited 2020Sep 24)

7. Karan A, Negandhi H, Nair R, Sharma A, Tiwari $\mathrm{R}$, Zodpey S. Size, composition and distribution of human resource for health in India: New estimates using National Sample Survey and Registry data [Internet]. 2020 [cited 24 September 2020]. Available from: http://doi: 10.1136/bmjopen-2018025979BMJ Open. 2019;9(4):e025979. 